\title{
O empreendedorismo de negócio na enfermagem brasileira: uma revisão integrativa
}

\author{
Business entrepreneurship in brazilian nursing: an integrative review \\ Emprendimiento empresarial en enfermería brasileña: una revisión integrativa
}

Recebido: 02/03/2021 | Revisado: 09/03/2021 | Aceito: 13/03/2021 | Publicado: 20/03/2021

Brenda Tanielle Dutra Barros

ORCID: https://orcid.org/0000-0002-3184-050X

Centro Universitário Metropolitano da Amazônia, Brasil

E-mail: brendatanielle.enf@gmail.com

Ana Gracinda Ignácio Silva

ORCID: https://orcid.org/0000-0001-6439-7842

Centro Universitário Metropolitano da Amazônia, Brasil

E-mail: anagracinda08@gmail.com

Marildete da Conceição Paula

ORCID: https://orcid.org/0000-0001-9092-4693

Centro Universitário Metropolitano da Amazônia, Brasil

E-mail: marypaula72@hotmail.com

Catarina Santos Ramos

ORCID: https://orcid.org/0000-0002-2376-8333

Centro Universitário Metropolitano da Amazônia, Brasil

E-mail: catramosblue@gmail.com

Irany Almeida Silva dos Santos

ORCID: https://orcid.org/0000-0002-0793-9307

Centro Universitário Metropolitano da Amazônia, Brasil

E-mail: iranyalmeida@hotmail.com

Rômulo Leno Miranda Barros

ORCID: https://orcid.org/0000-0003-1802-4521

Universidade da Amazônia, Brasil

E-mail: romuloleno@ hotmail.com

Tatiana Fabíola da Silva Lima

ORCID: https://orcid.org/0000-0001-5966-9727

Centro Universitário Metropolitano da Amazônia, Brasil

E-mail: tatiana.fs.lima2@gmail.com

Virgínia Mercês Lara Pessoa Oliveira

ORCID: https://orcid.org/0000-0002-4417-637X

Centro Universitário Metropolitano da Amazônia, Brasil

E-mail: virginiaoliveira@famaz.edu.br

Rogério Oliveira Bailão

ORCID: https://orcid.org/0000-0003-3047-5077

Escola Superior da Amazônia, Brasil

E-mail: rogerio_bailao@hotmail.com

Luceny Oliveira Mendes

ORCID: https://orcid.org/0000-0003-0505-9493

Centro Universitário Metropolitano da Amazônia, Brasil

E-mail: lumetais08@hotmail.com

Aline Costa Martins

ORCID: https://orcid.org/0000-0002-8022-3444

Faculdade Pan Amazônica, Brasil

E-mail: alinemartinsenfa@gmail.com

Gessica da Silva Farias Viana

ORCID: https://orcid.org/0000-0001-8377-0593

Centro Universitário Metropolitano da Amazônia, Brasil

E-mail: gessicadasilca15@hotmail.com

Rosana Cristina Coqueiro Campos

ORCID: https://orcid.org/0000-0003-2719-7248

Centro Universitário Metropolitano da Amazônia, Brasil

E-mail: rosanacampos06@yahoo.com.br

Ana Mara Franco Almeida Couto

ORCID: https://orcid.org/0000-0003-2871-6134

Faculdade Pan Amazônica, Brasil

E-mail: maraanafranco@gmail.com

José Eduardo Rezende Campos

ORCID: https://orcid.org/0000-0002-4070-8543

Centro Universitário Metropolitano da Amazônia, Brasil

E-mail: educamposjrc@gmail.com 


\title{
Resumo
}

O Empreendedorismo na Enfermagem representa a busca por atividades não exploradas, melhores remunerações e articulação estratégica para resolutividade de problemas vinculados à profissão. $\mathrm{O}$ estudo teve como objetivo descrever como o empreendedorismo de negócios tem se delineado na enfermagem e quais são as possibilidades de atuação empreendedora do enfermeiro. Trata-se de um estudo do tipo revisão integrativa de literatura com abordagem qualitativa. Como critérios de inclusão definiu-se: artigos primários, publicados na íntegra, em língua portuguesa, no período de 2011 a 2021; como critérios de exclusão: artigos que não se referiram ao contexto brasileiro e ao objeto proposto e estudos de revisão teórica. A coleta de dados foi realizada, nas bases de dados: Biblioteca Virtual em Saúde (BVS), Literatura Latino-americana e do Caribe em Saúde (LILACS), Scientific Electronic Library Online (SciELO). O estudo foi composto por oito artigos com nível de evidência de estudos 4. Os resultados foram apresentados a partir de duas categorias temáticas: O perfil do empreendedorismo de negócio no Brasil e Características do enfermeiro empreendedor no Brasil. Observa-se que o perfil do empreendedorismo de negócio na enfermagem brasileira, está concentrado nas grandes capitais, registradas como atividade de enfermagem e que estes enfermeiros empreendedores são predominantemente do sexo feminino, com idade entre 26 a 56 anos, com alguma especialização. Conclui-se que existe uma lacuna em relação ao conhecimento do empreendedorismo de negócios na enfermagem brasileira, sendo necessário o incremento de estudos que demonstrem as experiências exitosas dos enfermeiros na área.

Palavras-chave: Empreendedorismo; Negócios; Enfermagem; Inovação.

\begin{abstract}
Entrepreneurship in Nursing represents the search for unexplored activities, better remuneration and strategic articulation for solving problems related to the profession. The study aimed to describe how business entrepreneurship has been outlined in nursing and what are the possibilities for entrepreneurial performance of nurses. This is an integrative literature review study with a qualitative approach. The inclusion criteria were defined as: primary articles, published in full, in Portuguese, in the period from 2011 to 2021; as exclusion criteria: articles that did not refer to the Brazilian context and the proposed object and theoretical review studies. Data collection was carried out in the databases: Virtual Health Library (VHL), Latin American and Caribbean Health Literature (LILACS), Scientific Electronic Library Online (SciELO). The study consisted of eight articles with an evidence level of 4 studies. The results were presented from two thematic categories: The profile of business entrepreneurship in Brazil and Characteristics of the entrepreneur nurse in Brazil. It is observed that the profile of business entrepreneurship in Brazilian nursing is concentrated in large capitals, registered as a nursing activity and that these entrepreneur nurses are predominantly female, aged between 26 and 56 years, with some specialization. It is concluded that there is a gap in relation to the knowledge of business entrepreneurship in Brazilian nursing, being it is necessary to increase studies that demonstrate the successful experiences of nurses in the area.
\end{abstract}

Keywords: Entrepreneurship; Business; Nursing; Innovation.

\section{Resumen}

El Emprendimiento en Enfermería representa la búsqueda de actividades inexploradas, mejor remuneración y articulación estratégica para la resolución de problemas relacionados con la profesión. El estudio tuvo como objetivo describir cómo se ha perfilado el emprendimiento empresarial en enfermería y cuáles son las posibilidades de desempeño empresarial de las enfermeras. Se trata de un estudio de revisión de la literatura integradora con un enfoque cualitativo. Los criterios de inclusión se definieron como: artículos primarios, publicados íntegramente, en portugués, en el período de 2011 a 2021; como criterio de exclusión: artículos que no se refirieron al contexto brasileño y al objeto propuesto y estudios de revisión teórica. La recolección de datos se realizó en las bases de datos: Biblioteca Virtual en Salud (BVS), Literatura de Salud de América Latina y el Caribe (LILACS), Biblioteca Electrónica Científica en Línea (SciELO). El estudio consistió en ocho artículos con un nivel de evidencia de 4 estudios, los resultados fueron presentados a partir de dos categorías temáticas: El perfil del emprendimiento empresarial en Brasil y Características de la enfermera emprendedora en Brasil. Se observa que el perfil del emprendimiento empresarial en la enfermería brasileña se concentra en grandes capitales, registrados como actividad de enfermería y que estos enfermeros emprendedores son predominantemente mujeres, con edades entre 26 y 56 años, con alguna especialización. Se concluye que existe una brecha en relación al conocimiento del emprendimiento empresarial en la enfermería brasileña, siendo necesario incrementar los estudios que demuestren las experiencias exitosas de los enfermeros en el área.

Palabras clave: Emprendimiento; Negocios; Enfermería; Innovación.

\section{Introdução}

Entre as novas perspectivas que se apresenta, o empreendedorismo é elucidado como um movimento gerado pela pessoa empreendedora que tem como característica a coragem para assumir riscos, a visão diferenciada das situações, a criatividade para criar e a inovação para construir algo novo mediante uma oportunidade (Dornelas, 2016). Na área da 
Enfermagem esse modo transformador de pensar apareceu mais fortemente no século atual, porém ainda de maneira sutil (Moura \& Brum, 2017).

O Empreendedorismo na Enfermagem representa busca por atividades não exploradas, melhores remunerações e articulação estratégica para resolutividade de problemas vinculados à profissão. Três princípios são associados a um perfil empreendedor. Em primeiro lugar vêm à necessidade de realização pessoal, a qual estimula a diferenciação profissional no direcionamento da excelência. Em segundo encontramos a disposição para assumir riscos: financeiros e de demais ordens. E, por último, a autoconfiança, ao sentir que pode enfrentar desafios ao longo do empreendimento (Araújo \& Nunes, 2018).

O interesse pelo tema iniciou através de uma pesquisa feita por uma integrante do grupo que buscou entender quais as opções de atuação e tendências que o mercado de trabalho oferece para os recém-formados, nessa pesquisa constatou-se que a maior procura de oportunidade de emprego é para a assistência à saúde, porém, tendo como base as experiências cotidianas, percebeu-se que as contratações nos hospitais, principalmente nos públicos, não são suficientes para atender à demanda de profissionais do mercado de trabalho.

Além disso, observa-se atualmente no Brasil um cenário de intensiva mercantilização do setor da saúde e de transferência de fundo público para o setor privado, o que vem ditando novos rumos ao mercado de trabalho do enfermeiro, rumos estes que devem ser levados em consideração pelos futuros profissionais (Colichi \& Lima, 2018).

Considerando tais aspectos questionou-se: quais são as possibilidades de atuação no empreendedorismo de negócio da enfermagem brasileira, evidenciado na literatura cientifica dos últimos dez anos?

O estudo se justifica, pois, no Brasil ainda há poucos estudos que abordam o empreendedorismo de negócios na área da enfermagem, estando mais focados no empreendedorismo social, isso sinaliza a necessidade de ampliar as discussões sobre o conceito de empreendedorismo na enfermagem e conhecer quais as tipologias, áreas e/ou setores de atuação encontram-se os enfermeiros empreendedores (Copelli, Erdmann \& Santos, 2019). Assim, justifica-se a necessidade de ampliar o conhecimento acerca do empreendedorismo de negócios entre enfermeiros, buscando conhecer as características das atividades empreendedoras e o perfil desses enfermeiros a fim de se entender suas potencialidades empreendedoras (Chagas et al., 2018).

Isso é relevante, visto que hoje o trabalho do enfermeiro vai além do cuidar na área hospitalar, ele tem que estar preparado para cuidar, administrar, gerenciar, entre outras atividades a serem desenvolvidas por ele. Portanto, no contexto do mundo moderno, o empreendedor tem recebido destaque, por ter entre as suas virtudes competências empreendedoras (Alexandre et al., 2019).

O estudo objetivou descrever como o empreendedorismo de negócios tem se delineado na enfermagem e quais são as possibilidades de atuação empreendedora do enfermeiro, a partir de evidências científicas em periódicos nacionais, publicados no período entre 2011 a 2021.

\section{Metodologia}

A presente pesquisa baseia-se em um estudo do tipo revisão integrativa de literatura (RIL), com abordagem qualitativa. A revisão integrativa está presente dentro categoria das revisões sistemáticas, ela propicía a síntese de conhecimento e amplia a visão sobre os artigos científicos já publicados, fundamentando-se em conteúdos e informações baseadas nos diversos saberes (Souza, Silva \& Carvalho, 2010; Lima et al., 2021). Com relação a pesquisa qualitativa, esta demonstra, como principal recurso, o próprio pesquisador e, em seus dados, ressalta a preferência pelo modelo descritivo dando ênfase a importância de demonstrar os indivíduos participantes como atores principais de uma pesquisa (Pereira et al., 2018). 
A coleta de dados foi realizada, nas bases de dados: Biblioteca Virtual em Saúde (BVS), Literatura Latino-Americano e do Caribe em Ciências da Saúde (LILACS), Scientific Electronic Library Online (SciELO), que compreendeu o período de 2011 a 2021.

Seguindo as seis fases do processo de elaboração de Revisão Integrativa de Literatura $1^{\circ}$ Etapa - identificação do tema e seleção da hipótese ou questão de pesquisa para a elaboração da revisão integrativa; $2^{\circ}$ Etapa - Procurar a melhor evidência; $3^{\circ}$ Etapa - Avaliar criticamente as evidências; $4^{\circ}$ Etapa - Integrar as evidências; $5^{\circ}$ Etapa - discussão dos resultados; $6^{\circ}$ Etapa - apresentação da síntese do conhecimento produzido; revisão/síntese do conhecimento (Teixeira et al., 2014; Botelho, Cunha \& Macedo, 2011).

$\mathrm{Na}$ primeira etapa elaborou-se a seguinte questão de pesquisa: Quais são as possibilidades de atuação no empreendedorismo de negócio da enfermagem brasileira, evidenciado na literatura cientifica dos últimos dez anos?

Para sua elaboração foi utilizada a estratégia PICO, que representa um acrônimo para Paciente, Intervenção, Comparação e “Outcomes” (desfecho), utilizado na Prática Baseada em Evidências (PBE) (Santos, Pimenta \& Nobre, 2007). Por se tratar de um estudo com abordagem qualitativa, seguiu-se o recomendado pelo Joanna Briggs Institutte, que recomenda uma adaptação desse anagrama onde, em PICO, P corresponde aos participantes, o I, o fenômeno de interesse e CO ao contexto do estudo (Santos, Secoli \& Püschel, 2018). Nesse sentido, o P corresponde aos enfermeiros empreendedores; o I corresponde ao empreendedorismo de negócios na enfermagem; CO corresponde ao empreendedorismo de negócios na enfermagem no contexto brasileiro, na literatura dos últimos dez anos

Na segunda etapa do estudo, foram utilizadas as palavras-chave "Enfermagem", "Empreendedorismo", "Inovação", "negócios", e como estratégia de busca nas bases de dados, utilizou-se o cruzamento dos descritores com utilização do operadores booleanos "And"; “Or”. Fazendo o seguinte cruzamento: enfermagem AND ou OR negócios, enfermagem AND ou OR inovação, enfermagem AND ou OR empreendedorismo e enfermagem AND ou OR empreendedorismo de negócios.

Como critérios de inclusão definiu-se: artigos primários, publicados na íntegra, na língua portuguesa do Brasil que se relacione à temática e delimitando nos últimos 10 anos (2011 a 2021). Como critérios de exclusão: artigos que não se referirem ao contexto brasileiro e objeto proposto, estudos de revisão teórica.

$\mathrm{Na}$ terceira etapa do estudo analisou-se criticamente os estudos selecionados para avaliar e categorizar os níveis de evidências. Todos os estudos foram de nível 4, caracterizado de forma hierárquica, adotando-se a hierarquia das evidências segundo a classificação da abordagem metodológica adotada, em relação ao delineamento de pesquisa. A amostra foi composta com estudos descritivos (não-experimentais) e com abordagem qualitativa ou quantitativa (Soares et al., 2014).

Para extrair os dados dos artigos selecionados utilizou-se o formulário de Ursi \& Galvão (2015) incluindo: definição dos sujeitos, metodologia, tamanho da amostra, mensuração de variáveis, método de análise e conceitos bases empregadas (Soares et al., 2014).

$\mathrm{Na}$ quarta etapa organizou-se a incorporação das evidências dos artigos selecionados, para tal elaborou-se quadros sínteses (ver Quadro síntese 1 e 2) que proporcionaram a análise das informações e categorização dos conteúdos analisados. A base de um resumo sintetizado pode abranger conteúdos verbais, conceitos, sínteses textuais, memorandos, padrões de respostas e proporcionar a interligação em rede ads informações em volto de um um assunto principal (Botelho, Cunha \& Macedo, 2011).

Para cumprir a quinta e sexta etapas da revisão os resultados foram interpretados e discutidos, finalizando com a apresentação da revisão com abordagem qualitativa. 


\section{Resultados}

A presente pesquisa baseia-se em um estudo do tipo revisão integrativa de literatura (RIL), com abordagem qualitativa. A revisão integrativa está presente dentro categoria das revisões sistemáticas, ela propicía a síntese de conhecimento e amplia a visão sobre os artigos científicos já publicados, fundamentando-se em conteúdos e informações baseadas nos diversos saberes (Souza, Silva \& Carvalho, 2010; Lima et al., 2021). Com relação a pesquisa qualitativa, esta demonstra, como principal recurso, o próprio pesquisador e, em seus dados, ressalta a preferência pelo modelo descritivo dando ênfase a importância de demonstrar os indivíduos participantes como atores principais de uma pesquisa (Pereira et al., 2018).

A coleta de dados foi realizada, nas bases de dados: Biblioteca Virtual em Saúde (BVS), Literatura Latino-Americano e do Caribe em Ciências da Saúde (LILACS), Scientific Electronic Library Online (SciELO), que compreendeu o período de 2011 a 2021.

Seguindo as seis fases do processo de elaboração de Revisão Integrativa de Literatura $1^{\circ}$ Etapa - identificação do tema e seleção da hipótese ou questão de pesquisa para a elaboração da revisão integrativa; $2^{\circ}$ Etapa - Procurar a melhor evidência; $3^{\circ}$ Etapa - Avaliar criticamente as evidências; $4^{\circ} \mathrm{Etapa}$ - Integrar as evidências; $5^{\circ}$ Etapa - discussão dos resultados; $6^{\circ}$ Etapa - apresentação da síntese do conhecimento produzido; revisão/síntese do conhecimento (Teixeira et al., 2014; Botelho, Cunha \& Macedo, 2011).

$\mathrm{Na}$ primeira etapa elaborou-se a seguinte questão de pesquisa: Quais são as possibilidades de atuação no empreendedorismo de negócio da enfermagem brasileira, evidenciado na literatura cientifica dos últimos dez anos?

Para sua elaboração foi utilizada a estratégia PICO, que representa um acrônimo para Paciente, Intervenção, Comparação e "Outcomes" (desfecho), utilizado na Prática Baseada em Evidências (PBE) (Santos, Pimenta \& Nobre, 2007). Por se tratar de um estudo com abordagem qualitativa, seguiu-se o recomendado pelo Joanna Briggs Institutte, que recomenda uma adaptação desse anagrama onde, em PICO, P corresponde aos participantes, o I, o fenômeno de interesse e CO ao contexto do estudo (Santos, Secoli \& Püschel, 2018). Nesse sentido, o P corresponde aos enfermeiros empreendedores; o I corresponde ao empreendedorismo de negócios na enfermagem; $\mathrm{CO}$ corresponde ao empreendedorismo de negócios na enfermagem no contexto brasileiro, na literatura dos últimos dez anos

Na segunda etapa do estudo, foram utilizadas as palavras-chave "Enfermagem", "Empreendedorismo", "Inovação", "negócios", e como estratégia de busca nas bases de dados, utilizou-se o cruzamento dos descritores com utilização do operadores booleanos "And"; "Or”. Fazendo o seguinte cruzamento: enfermagem AND ou OR negócios, enfermagem AND ou OR inovação, enfermagem AND ou OR empreendedorismo e enfermagem AND ou OR empreendedorismo de negócios.

Como critérios de inclusão definiu-se: artigos primários, publicados na íntegra, na língua portuguesa do Brasil que se relacione à temática e delimitando nos últimos 10 anos (2011 a 2021). Como critérios de exclusão: artigos que não se referirem ao contexto brasileiro e objeto proposto, estudos de revisão teórica.

$\mathrm{Na}$ terceira etapa do estudo analisou-se criticamente os estudos selecionados por dois autores, para evitar viéses e para avaliar e categorizar os níveis de evidências. Todos os estudos foram de nível 4, caracterizado de forma hierárquica, adotandose a hierarquia das evidências segundo a classificação da abordagem metodológica adotada, em relação ao delineamento de pesquisa. A amostra foi composta com estudos descritivos (não-experimentais) e com abordagem qualitativa ou quantitativa (Soares et al., 2014).

Para extrair os dados dos artigos selecionados utilizou-se o formulário de Ursi \& Galvão (2015) incluindo: definição dos sujeitos, metodologia, tamanho da amostra, mensuração de variáveis, método de análise e conceitos bases empregadas (Soares et al., 2014). 
$\mathrm{Na}$ quarta etapa organizou-se a incorporação das evidências dos artigos selecionados, para tal elaborou-se quadros sínteses (ver Quadro síntese 1 e 2) que proporcionaram a análise das informações e categorização dos conteúdos analisados. A base de um resumo sintetizado pode abranger conteúdos verbais, conceitos, sínteses textuais, memorandos, padrões de respostas e proporcionar a interligação em rede ads informações em volto de um um assunto principal (Botelho, Cunha \& Macedo, 2011). Para cumprir a quinta e sexta etapas da revisão os resultados foram interpretados e discutidos, finalizando com a apresentação da revisão com abordagem qualitativa.

Obteve-se um total de 11.223 artigos, somando-se as três bases de dados, aplicando-se os filtros (ano de publicação, tipo de estudo e língua - nas 3 bases) foram excluídos 11.215 estudos. Os resultados obtidos foram dispostos ao Fluxograma 1 PRISMA (Moher et al., 2009) a seguir:

Fluxograma 1: Fluxograma PRISMA contendo as etapas de inclusão dos artigos.
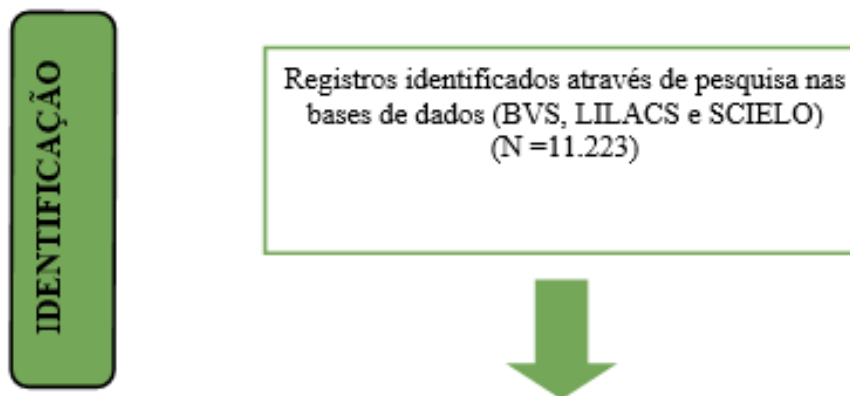

Registros adicionados por meio de outros critérios/métodos $(\mathrm{N}=00)$

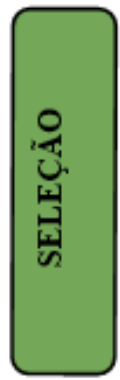

Registros filtro de periódico nas bases de dados (excluídos) $(\mathrm{N}=8.200)$

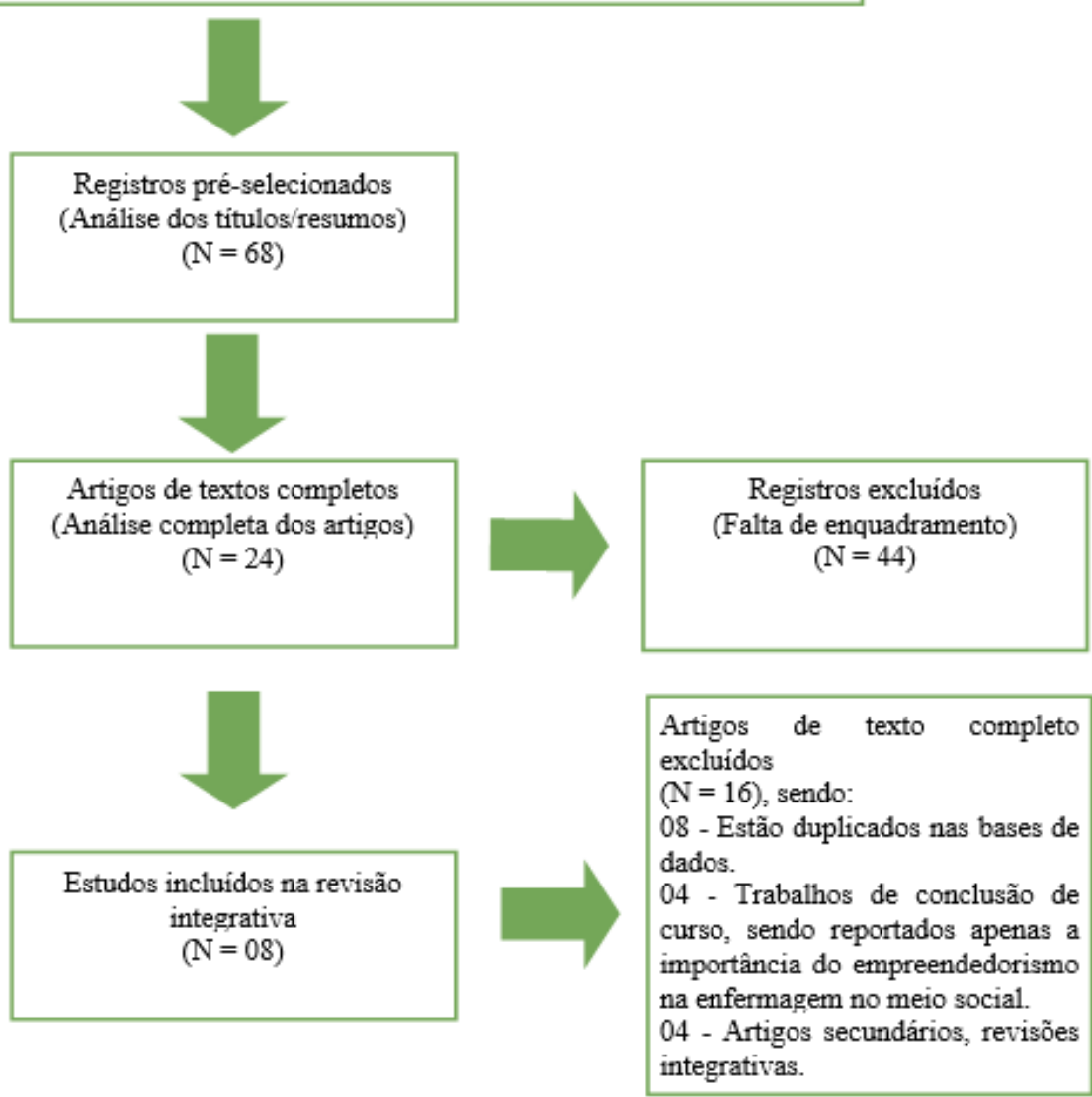


A partir da análise dos artigos dispostos no fluxograma e da identificação amostral de 8 (oito) produções selecionadas, os estudos foram agrupados e postos nos quadros-síntese, onde foi utilizado o instrumento adaptado de Ursi e Galvão (2015). Selecionou-se os intens: Título do artigo; Autores; Local da pesquisa; Metodologia e Nível de evidência, para o Quadro-síntese 1 e Título; Objetivos e Resultados, para o Quadro-síntese 2.

Quadro síntese 1: Caracterização dos artigos.

\begin{tabular}{|c|c|c|c|c|}
\hline $\begin{array}{l}\text { TÍTULO DO } \\
\text { ARTIGO }\end{array}$ & AUTORES & $\begin{array}{l}\text { LOCAL DA } \\
\text { PESQUISA }\end{array}$ & METODOLOGIA & $\begin{array}{c}\text { NÍVEL DE } \\
\text { EVIDENCIA }\end{array}$ \\
\hline $\begin{array}{c}\text { Incubadora de } \\
\text { Aprendizagem: ferramenta } \\
\text { indutora do } \\
\text { empreendedorismo na } \\
\text { Enfermagem }\end{array}$ & $\begin{array}{l}\text { Dirce Stein Backes, Marielle } \\
\text { Kulakowski Obem, Simone } \\
\text { Barbosa Pereira, Carine } \\
\text { Alves Gomes, Marli Terezinha } \\
\text { Stein Backes, Alacoque } \\
\text { Lorenzini Erdmann. } \\
\end{array}$ & Rio Grande do Sul & $\begin{array}{l}\text { Estudo exploratório-descritivo, } \\
\text { orientado pela abordagem } \\
\text { qualitativa, pela técnica de grupo } \\
\text { focal. }\end{array}$ & Nível 4 \\
\hline $\begin{array}{l}\text { O empreendedorismo de } \\
\text { negócios entre enfermeiros }\end{array}$ & $\begin{array}{l}\text { Sabrina de Cássia Chagas, Priscila } \\
\text { Néria Milagres, Mariana Cristina } \\
\text { Rodrigues Silva, Ricardo Bezerra } \\
\text { Cavalcante, Patrícia Peres de } \\
\text { Oliveira, Regina Consolação dos } \\
\text { Santos }\end{array}$ & Minas Gerais & $\begin{array}{c}\text { Estudo de caso com abordagem } \\
\text { quantitativa, apoiado nos conceitos } \\
\text { de Schumpeter. }\end{array}$ & Nível 4 \\
\hline $\begin{array}{l}\text { A arte e ciência do cuidar, } \\
\text { alteridade, estabelecidos e } \\
\text { outsiders na autonomia do } \\
\quad \text { enfermeiro como } \\
\quad \text { profissional liberal }\end{array}$ & $\begin{array}{c}\text { Erica Karanine Bezerra Silva, José } \\
\text { Nilton Oliveira da Silva Junior, } \\
\text { Nelson Miguel Galindo Neto, } \\
\text { Leonardo Silva da Costa, Kleber } \\
\text { Fernando Rodrigues, Ana Carla } \\
\text { Silva Alexandre }\end{array}$ & $\begin{array}{c}\text { Nas cidades de } \\
\text { Pesqueira, Arcoverde } \\
\text { e Belo Jardim } \\
\text { - Estado de } \\
\text { Pernambuco }\end{array}$ & $\begin{array}{l}\text { Estudo qualitativo à luz dos } \\
\text { conceitos de "estabelecidos", } \\
\text { outsiders, "alteridade" e } \\
\text { “estigmatização", dos teóricos } \\
\text { Norbert Elias, Anthony Giddens e } \\
\text { Goffman, com análise de conteúdo } \\
\text { de Bardin. }\end{array}$ & Nível 4 \\
\hline $\begin{array}{l}\text { Ações empreendedoras em } \\
\text { enfermagem: desafios de } \\
\text { enfermeiras em posição } \\
\text { estratégica de liderança. }\end{array}$ & $\begin{array}{c}\text { Samanta Andresa Richter, } \\
\text { Edemilson Pichek dos Santos, } \\
\text { Dagmar Elaine Kaiser, } \\
\text { Claudia Capellari, } \\
\text { Gímerson Erick Ferreira }\end{array}$ & Rio Grande do Sul & $\begin{array}{c}\text { Abordagem qualitativa, de caráter } \\
\text { descritivo e exploratório, ancorado } \\
\text { numa proposta dialética }\end{array}$ & Nível 4 \\
\hline $\begin{array}{c}\text { O empreendedorismo como } \\
\text { uma ferramenta para atuação } \\
\text { do enfermeiro }\end{array}$ & $\begin{array}{l}\text { Geilsa Soraia Cavalcanti Valente } \\
\text { Ana Cristina da Paixão Silva, } \\
\text { Gabriel Luís Cavalcanti Valente, }\end{array}$ & Rio de Janeiro & $\begin{array}{l}\text { Estudo exploratório, descritivo, de } \\
\text { abordagem quantitativa }\end{array}$ & Nível 4 \\
\hline $\begin{array}{l}\text { Perfil empreendedor entre } \\
\text { residentes de Enfermagem }\end{array}$ & $\begin{array}{l}\text { Andressa Martins dias Ferreira, } \\
\text { mariana Ângela rosareis, João } \\
\text { Lucas campos de oliveira, Maria } \\
\text { do Carmo Fernandez Lourenço } \\
\text { Haddad, Marli Terezinha oliveira } \\
\text { vannuchi. Ferreira }\end{array}$ & Paraná & $\begin{array}{c}\text { Estudo transversal, descritivo, de } \\
\text { abordagem quantitativa. }\end{array}$ & Nível 4 \\
\hline $\begin{array}{c}\text { Tendências empreendedoras } \\
\text { dos enfermeiros de um } \\
\text { hospital universitário }\end{array}$ & $\begin{array}{c}\text { Fabiana gallo costa, helena } \\
\text { heidtmann vaghettib, Daniela } \\
\text { Faustino Gonçalves martinello, } \\
\text { Daniel pinho mendes, Alexsandra } \\
\text { chaves terra, Simone quadros } \\
\text { Alvarez, Luiz augusto pinto lemos. }\end{array}$ & Rio Grande do Sul & $\begin{array}{l}\text { Estudo de abordagem quantitativa, } \\
\text { transversal contemporâneo }\end{array}$ & Nível 4 \\
\hline
\end{tabular}




\begin{tabular}{|c|c|c|c|c|}
\hline $\begin{array}{l}\text { Tendência empreendedora } \\
\text { de estudantes de } \\
\text { enfermagem: comparação } \\
\text { entre alunos de graduação } \\
\text { iniciantes e concluintes }\end{array}$ & $\begin{array}{c}\text { Liana Amorim Corrêa Trotte, José } \\
\text { Luís Guedes dos Santos, Caroline } \\
\text { Ferreira Neris Sarat, Maria Gefé da } \\
\text { Rosa Mesquita, Marluci Andrade } \\
\text { Conceição Stipp, Patrícia de Souza, } \\
\text { Quézia Guedes de Mello Duarte, } \\
\text { Bruno de Campos Gobato, Claudia } \\
\text { Feio da Maia Lima }\end{array}$ & $\begin{array}{l}\text { Várias regiões do } \\
\text { Brasil }\end{array}$ & $\begin{array}{l}\text { Pesquisa quantitativa, de caráter } \\
\text { transversal. }\end{array}$ & Nível 4 \\
\hline
\end{tabular}

Fonte: Autores.

Quadro Síntese 2. Contribuições dos estudos.

\begin{tabular}{|c|c|c|}
\hline TÍTULOS & OBJETIVOS & RESULTADOS \\
\hline $\begin{array}{l}\text { Incubadora de } \\
\text { Aprendizagem: } \\
\text { ferramenta indutora do } \\
\text { empreendedorismo na } \\
\text { Enfermagem }\end{array}$ & $\begin{array}{l}\text { Conhecer as } \\
\text { contribuições da } \\
\text { Incubadora de } \\
\text { Aprendizagem no } \\
\text { processo de educação } \\
\text { permanente em } \\
\text { saúde. }\end{array}$ & $\begin{array}{l}\text { Perante a análise dos dados foram identificadas } 3 \text { categorias: Incubadora de Aprendizagem - Espaço de } \\
\text { acolhida e integração; Ferramenta instigadora e ampliadora de possibilidades; Estratégia de educação } \\
\text { continuada e permanente: Nas falas dos participantes, afirmaram que a Incubadora de Aprendizagem } \\
\text { atingiu os seus objetivos iniciais, que foram: ser um espaço de acolhida, partilha e convivência, inclusive } \\
\text { para os novos profissionais. Mesmo não compreendendo os significados do termo Incubadora e ou do } \\
\text { processo de incubação, o estudo apontou que todos se motivaram a participar do proposto; Para os } \\
\text { participantes, a incubadora de aprendizagem mostriu a possibilidade de ser e fazer a diferença. } \\
\text { Reconheceram que muitos trabalhadores tendem a se acomodar no seu modo de pensar e agir, o que cria } \\
\text { fazendo com que ajam de forma mecânica. A Incubadora os instigou e motivou a mudar a visão } \\
\text { bitolada e a saírem da zona de conforto, isto é, de fazer as coisas de forma rotineira e mecânica; A Ainda } \\
\text { modificou a visão das tradicionais reuniões ou treinamentos, que reproduziam saberes e práticas com } \\
\text { pouco interativas e reflexivas. Os participantes reconhecem e reavaliam as suas atitudes e prática, de } \\
\text { forma crítico-reflexiva e se propõem ao aprendizado continuo e permanente. }\end{array}$ \\
\hline $\begin{array}{l}\text { O empreendedorismo } \\
\text { de negócios entre } \\
\text { enfermeiros }\end{array}$ & $\begin{array}{c}\text { Caracterizar o } \\
\text { empreendedorismo } \\
\text { de negócios entre } \\
\text { enfermeiros. }\end{array}$ & $\begin{array}{l}\text { Os enfermeiros necessitavam fortalecer algumas características comportamentais como: ir ao encontro } \\
\text { de informações, planejar e monitorar sistematicamente e persuasivamente e ampliar suas rede de } \\
\text { contatos. Relacionado ao perfil da equipe entrevistada, } 70 \% \text { eram do sexo feminino, na faixa etária entre } \\
30 \text { a } 40 \text { anos. Todos realizaram graduação em instituição privada. Observou-se } 40 \% \text { dos enfermeiros } \\
\text { possuem mais de uma especialização, entretanto estas nem sempre estão ligadas à sua área de atuação no } \\
\text { empreendimento. Ressalta-se a alta lucratividade mensal desses empreendedores, que variou entre R\$ } \\
1.800,00 \text { a } \mathrm{R} \$ 85.000 \text {. Do total de entrevistados, } 50 \% \text { exercem atualmente outra atividade além do seu } \\
\text { empreendimento. Todos já trabalharam em outros locais antes de seus empreendimentos e } 70 \% \\
\text { apresentam CNPJ e razão sociais devidamente registradas em órgão competente. Em relação às CCEs } \\
\text { dos enfermeiros entrevistados, considerando o questionário proposto por McClelland e sua pontuação } \\
\text { recomendada (15 a } 25 \text { ), observa-se que o envolvimento, abertura de metas e independência e } \\
\text { autoconfiança estiveram como as características com maiores médias. }\end{array}$ \\
\hline $\begin{array}{l}\text { A arte e ciência do } \\
\text { cuidar, alteridade, } \\
\text { estabelecidos e } \\
\text { outsiders na autonomia } \\
\text { do enfermeiro como } \\
\text { profissional liberal }\end{array}$ & $\begin{array}{l}\text { Compreender o } \\
\text { processo de } \\
\text { construção da } \\
\text { autonomia do } \\
\text { enfermeiro como } \\
\text { profissional liberal }\end{array}$ & $\begin{array}{l}\text { Puderam ser identificados enfermeiros autônomos que, estavam dispostos como outsiders e que eram } \\
\text { vítimas de estigmas pelos profissionais, população e pelos próprios outsiders. Foram encontrados } 6 \\
\text { (seis) enfermeiros e enfermeiras profissionais liberais, onde } 66,67 \% \text { foram entrevistados. Dos } \\
\text { entrevistados, } 75 \% \text { possuíam consultórios ou empresa em Centro de Especialidades (Centro Médico) e } \\
25 \% \text { trabalhavam atendendo em domicílio. Todos atuavam na área de Enfermagem dermatológica. Dos } \\
\text { entrevistados, } 25 \% \text { começaram a atuar de forma autônoma em } 2012,50 \% \text { iniciaram o empreendimento } \\
\text { em } 2013 \text { e } 25 \% \text {, em } 2014 \text {. Já no quesito motivação, os enfermeiros relataram que foram levados ao } \\
\text { empreendedorismo devido à necessidade de profissional na região e à demanda de pacientes, e por conta } \\
\text { do retorno financeiro. Dessa forma, os enfermeiros e enfermeiras que optem por se tornar profissionais } \\
\text { liberais devem compreender o processo que os outsiders sofrem para conquistar seu espaço. É } \\
\text { extremamente temerário tentar colocar-se como estabelecido caso não se enxergue todo o preconceito de } \\
\text { parte da população e de segmentos das demais profissões da saúde, evitando-se erroneamente o } \\
\text { necessário enfrentamento por meio de posturas de alteridade e saber científico. }\end{array}$ \\
\hline $\begin{array}{l}\text { Ações empreendedoras } \\
\text { em enfermagem: } \\
\text { desafios de enfermeiras } \\
\text { em posição estratégica } \\
\text { de liderança }\end{array}$ & $\begin{array}{l}\text { Conhecer os desafios } \\
\text { ao desenvolvimento } \\
\text { de ações } \\
\text { empreendedoras na } \\
\text { perspectiva de } \\
\text { enfermeiras em } \\
\text { posição estratégica de } \\
\text { liderança }\end{array}$ & $\begin{array}{l}\text { As enfermeiras participantes possuíam média de idade de } 40,5 \text { anos; tempo médio na posição de } \\
\text { liderança de } 5,2 \text { anos; } 50 \% \text { atuavam em serviços da rede pública. Todas informaram que o principal } \\
\text { motivo pelo qual foram escolhidas para ocupar a posição se deu em razão do tempo de trabalho na } \\
\text { instituição ou serviço. Quanto à formação profissional, } 10(83,33 \%) \text { possuíam título de pós- } \\
\text { graduação lato sensu (especialização), e } 2(16,66 \%) \text { apresentavam qualificação em nível de pós- } \\
\text { graduação stricto sensu (doutorado), concluído ou em andamento. Foi desvelado que as enfermeiras em } \\
\text { posição estratégica de liderança visualizam desafios importantes no desenvolvimento de ações } \\
\text { empreendedoras, representados pelas estruturas descritas nas categorias temáticas: Movimentos da ação } \\
\text { empreendedora por enfermeiras em posição estratégica de liderança; Empreender em posição estratégica } \\
\text { de liderança: situaçães (i)mobilizadoras; O aprender a empreender: desafios de uma responsabilidade } \\
\text { avançada. }\end{array}$ \\
\hline
\end{tabular}




\begin{tabular}{|c|c|c|}
\hline $\begin{array}{l}\text { O empreendedorismo } \\
\text { como uma ferramenta } \\
\text { para atuação do } \\
\text { enfermeiro }\end{array}$ & $\begin{array}{l}\text { Fazer a Identificação } \\
\text { dos aspectos que } \\
\text { indicam que o } \\
\text { enfermeiro é } \\
\text { empreendedor. } \\
\text { Analisar das } \\
\text { tendências } \\
\text { empreendedoras dos } \\
\text { enfermeiros. }\end{array}$ & $\begin{array}{l}\text { Caracterizou-se os níves de tendência empreendedora: nível de tendência empreendedora do } \\
\text { enefermeiro: } 44 \% \text {, "muito baixo", ou seja, apenas } 11 \text { atingiram a dimensão da tendência } \\
\text { empreendedora; } 32 \% \text { dos enfermeiros (igual a } 8 \text { participantes), atingiram duas dimensões, considerado } \\
\text { um nível "baixo". Só se considera nível de tendência empreendedora médio quando atinge-se três } \\
\text { dimensões, o que nos resultados representou } 4 \% \text { dos enfermeiros; apenas um participante atingiu as três } \\
\text { dimensões. Os cinco enfermeiros que conseguiram a média em quatro dimensões obtiveram o nível de } \\
\text { tendência empreendedora classificado como "alto" e somaram } 20 \% \text {. No último nível "muito alto", onde } \\
\text { se tem cinco dimensões empreendedoras, não houve pontuação (0\%). A partir dos resultados, os } \\
\text { enfermeiros que participaram precisam desenvolver as tendências empreendedoras. }\end{array}$ \\
\hline $\begin{array}{l}\text { Perfil empreendedor } \\
\text { entre residentes de } \\
\text { Enfermagem }\end{array}$ & $\begin{array}{l}\text { Identificar o perfil } \\
\text { empreendedor de } \\
\text { residentes de } \\
\text { enfermagem de uma } \\
\text { universidade pública. }\end{array}$ & $\begin{array}{l}\text { Dos } 60 \text { residentes abordados, } 57 \text { participaram do estudo. Destes, } 91 \% \text { eram do sexo feminino, com idade } \\
\text { média de } 24 \text { anos. A maioria foi graduada por instituições de ensino superior do estado do Paraná (75\%) } \\
\text { e em menor proporção pelo estado de São Paulo (14\%) e } 11 \% \text { por outros estados do Brasil. Observou-se } \\
\text { que apenas nas tendências de necessidade de sucesso e de impulso e determinação, a porcentagem de } \\
\text { participantes atingiu pontuação acima da média, sendo maior que } 50 \% \text {. Esse resultado indica que os } \\
\text { residentes possuíam tendência empreendedora insuficiente. Os residentes com mais idade e experiência } \\
\text { profissional apresentaram mais impulso e determinação. Talvez as tendências empreendedoras avaliadas } \\
\text { "negativamente" sejam resultantes da posição ainda de formação dos participantes, mas, considerando } \\
\text { que a residência é uma modalidade de capacitação profissional, esses resultados revelam que há } \\
\text { necessidade de revisão na formação dos enfermeiros. Vale ainda destacar a necessidade de os residentes } \\
\text { de enfermagem valorizarem seu papel na equipe e na instituição, exercendo suas atividades com } \\
\text { autonomia e criatividade, assumindo metas, reconhecendo suas competências para possibilitar a } \\
\text { prestação de assistência com qualidade }\end{array}$ \\
\hline $\begin{array}{c}\text { Tendências } \\
\text { empreendedoras dos } \\
\text { enfermeiros de um } \\
\text { hospital universitário }\end{array}$ & $\begin{array}{l}\text { Objetivou identificar } \\
\text { tendências } \\
\text { empreendedoras dos } \\
\text { enfermeiros em } \\
\text { hospital universitário } \\
\text { e fazer a relação com } \\
\text { idade, tempo de } \\
\text { trabalho e conclusão } \\
\text { do curso de } \\
\text { enfermagem. }\end{array}$ & $\begin{array}{l}\text { Os enfermeiros são em } 98,33 \% \text { mulheres, com idade entre } 27 \text { e } 56 \text { anos, sendo que } 50 \% \text { variam entre } \\
32,5 \text { e } 49,5 \text { anos. Em relação ao tempo da formação universitária, a amplitude é de } 29 \text { anos (entre } 1 \text { e } 30 \\
\text { anos), sendo que } 50 \% \text { oscilou entre } 10 \text { e } 22,5 \text { anos. Já no quesito tempo de trabalho no HU, o menor é } \\
\text { de } 1 \text { mês e o maior de } 24 \text { anos, sendo que na mesma unidade/setor, a média de permanência é de } 7 \text { anos, } \\
\text { com uma variação entre } 1 \text { e } 16 \text { anos. Observou-se que os enfermeiros com idade entre } 32,5 \text { e } 34,5 \text { anos } \\
\text { são aqueles que apresentam maior tendência empreendedora. Em contrapartida, os com idade superior a } \\
43 \text { anos demonstram um decréscimo da tendência empreendedora retomando- a e mantendo-a até a faixa } \\
\text { dos } 56 \text { anos, quando reinicia um novo declínio da pontuação. As evidências e discussões possibilitaram } \\
\text { o entendimento do fenômeno do empreendedorismo na realidade dos enfermeiros do hospital, mesmo } \\
\text { que a pesquisa tenha retratado um momento específico daquele espaço e sujeitos. Tem-se a clareza de } \\
\text { que outros estudos, que envolvam, concomitantemente, subjetividades da cultura e do clima } \\
\text { organizacional, também sejam pertinentes e complementares para maior imersão nesse universo. } \\
\text { Discussões internas sobre a questão dos riscos calculados e o seu papel para o melhor aproveitamento do } \\
\text { trabalho empreendedor também devem ser incentivadas e promovidas. }\end{array}$ \\
\hline $\begin{array}{l}\text { Tendência } \\
\text { empreendedora de } \\
\text { estudantes de } \\
\text { enfermagem: } \\
\text { comparação entre } \\
\text { alunos de graduação } \\
\text { iniciantes e concluintes }\end{array}$ & $\begin{array}{l}\text { Fazer a comparação } \\
\text { entre a tendência } \\
\text { empreendedora e } \\
\text { alunos iniciantes e } \\
\text { concluintes de cursos } \\
\text { de graduação em } \\
\text { enfermagem }\end{array}$ & $\begin{array}{l}\text { Os resultados apontaram que as pontuações dos alunos do nível iniciante estiveram abaixo da média em } \\
\text { todas dimensões do instrumento. Já os discentes do nível concluinte tiveram resultados acima da média } \\
\text { no teste da dimensão Impulso e determinação. Demonstrou-se as diferenças estatísticas significativas } \\
\text { relacionadas ao período do curso e a tendência empreendedora nas dimensões: Necessidade de } \\
\text { realização ( } \mathrm{p}=0,001 \text { ) e Impulso e determinação }(\mathrm{p}=0,000) \text {. Estes resultados mostraram a importância do } \\
\text { investimento das universidades no estímulo de uma cultura empreendedora no ensino superior em } \\
\text { enfermagem. }\end{array}$ \\
\hline
\end{tabular}

Fonte: Autores.

Após análise dos Quadros-sínteses 1 e 2, identificou-se duas categorias temáticas: O perfil do empreendedorismo de negócio no Brasil e Características do enfermeiro empreendedor no Brasil.

\section{Discussões}

\subsection{O perfil do empreendedorismo de negócios no Brasil}

Nesta categoria, identificou-se dois artigos que tiveram como objetivo identificar, caracterizar e comparar o empreendedorismo de negócios na área da enfermagem. No primeiro perfil, demonstram-se as razões e possibilidades para a enfermagem exercer o empreendedorismo; no segundo perfil, apontam-se a características fundamentais à ação empreendedora.

$\mathrm{O}$ enfermeiro tem infinitos motivos para escolher o caminho ao empreendedorismo. Em primeiro lugar, pela enfermagem ser uma área que tem uma visão holística, ampla e transversal das necessidades do paciente. Posteriormente, por ter competência de adentrar em novos espaços. E, por ultimo, independente de qualquer questão, o ser humano precisará de cuidados específicos e profissionais em algum momento da vida, e a profissão do cuidado é a enfermagem (Becks et al., 2015). 
Apesar dos vários motivos citados, que ressalta as várias possibilidades do cuidado de enfermagem, os estudos de Richter et al. (2019) demonstraram que os aspectos necessários à ação empreendedora, pontuado pelas enfermeiras participantes do estudo são a persistência organização, iniciativa, compromisso e visão a longo prazo. O mesmo autor ainda trouxe em seu estudo que estas características, nem sempre são possíveis de ser postas em prática, perante à falta de autonomia e independência destas profissionais.

Perante a nova realidade política, financeira e tecnológica, a enfermagem acaba tendo que se adequar a esse novo cenário de inovação das práticas profissionais, através da criação de tecnologias inovadoras inter e multidisciplinares. Sendo assim, a Enfermagem tem a atribuição de mover planos integradores que possam servir como base para tecnologias que visam o cuidado em saúde e o processo de ensino-aprendizagem (Becks et al., 2015).

As enfermeiras do estudo de Richter et al., (2019) relatam sobre a importância de se qualificar e se atualizar constantemente para poder permanecer no local que ocupam. O autor demonstra que a partir dessa perspectiva, a habilidade empreendedora das enfermeiras é diretamente proporcional ao propósito de se qualificar constantemente, a proatividade no desempenho das ações e criatividade para desenvolver novas oportunidades, no intuito de melhorar as práticas do cuidado em enfermagem.

Ainda no estudo de Richter et al., (2019), têm-se pontuado bastante a questão do que seria necessário para se obter êxito na liderança empreendedora e caracterizou-se a empatia e a inteligência emocional, elementos fundamentais ao bem-estar do indivíduo. As enfermeiras do estudo deste autor veêm no cuidado uma oportunidade positiva de se empreender, assim, servindocomo inspiração para sua equipe pois mostram-lhes o caminho para empreendimento.

Quanto aos serviços prestados, os autores acima citados, apontam que por serem áreas de assistência focada no indivíduo, as possíveis atividades são de atendimento em consultórios, clínicas, hospitais, ambulatórios e outros serviços públicos ou privados.

Em contrapartida, para dar continuidade ao desenvolvimento institucional e profissional, a enfermeiras demonstraram que na maior parte do tempo as questões culturais interferem no desenvolvimento do ato de empreender, por esta cultura desmerecer e desacreditar as habilidades e competências dessas profissionais de gerência. As participantes da pesquisa relataram não ter sofrido discriminação de gênero no que tange o desenvolvimento e implantação de projetos, porém reiteram que sua chefia imediata costuma obstaculizar a movimentação em torno do empreendedorismo, demonstrando um comportamento de preconceito por não acreditar na capacidade de gestão de mulheres (Richter et al., 2019).

À essência do que foi exposto, considera-se imprescindível que enfermeiras que ocupam cargos de liderança tenham a sapiência de projetar e transmitir condutas empreendedoras no trabalho em saúde, pois a visão cultural que se tinha era de que a enfermagem era apenas uma função unilateral, de cunho assistencialista (Richter et al., 2019).

\subsection{Características do enfermeiro empreendedor no brasil}

Dos estudos pesquisados seis (6) abordaram as características e referências empreendedoras da enfermagem, assim nesta categoria serão abordadas características pessoais, de remuneração e de tendências empreendedoras.

Em relação as características pessoais dos enfermeiros empreendedores ou com tendências empreendedoras, o sexo e a idade foram variáveis que coincidiram em todos os estudos, ou seja, há uma predominância do sexo feminino, e de idade entre 26 a 56 anos de enfermeiros que se interessam em empreender. Todos os enfermeiros têm alguma especialização, que nem sempre coincide com a área de negócios que atuam (Chagas et al., 2018).

O estudo de Costa et al., (2013) mostrou que os enfermeiros ou enfermeiras com idade entre 32,5 e 34,5 anos são profissionais que apresentam maior perfil empreendedor. Já aqueles com idade acima de 43 anos não apresentam ou não representam esta tendência empreendedora, prevalecendo a faixa até 56 anos, onde nasce um novo declínio da pontuação. Os 
enfermeiros que atuam há mais tempo apresentaram uma tendência empreendedora inferior aos demais, onde encontrou-se escores mais altos na tendência empreendedora no profissional com tempo de trabalho bem menor, entre 4 e 5 anos, havendo diminuição desta tendência após os 12 anos de serviços prestados. Ainda verificou-se que aqueles que tiveram boas pontuações em testes de tendência empreendedora durante a graduação, são os que tiveram tempo de conclusão da graduação ente 5 a 11 anos.

Enquanto, o estudo de Alexandre et al. (2019) identificou que há estigmas que rondam os enfermeiros que optam pelo trabalho autônomo na área e que estes estigmas advém dos profissionais da mesma área, da comunidade e também dos outsiders. Ainda neste estudo, identificou-se seis (6) enfermeiros liberais, onde 66,67\% foram entrevistados. Dos entrevistados, 75\% possuíam consultórios ou empresa em Centro de Especialidades (Centro Médico) e 25\% trabalhavam atendendo em domicílio. Todos atuavam na área de Enfermagem dermatológica, e 25\% começaram a atuar de forma autônoma em 2012, $50 \%$ iniciaram o empreendimento em 2013 e $25 \%$, em 2014.

Quanto as características relacionadas a remuneração, o estudo de Chagas et al., (2018) ressalta a alta lucratividade mensal desses empreendedores, que variou entre $\mathrm{R} \$ 1.800,00$ a $\mathrm{R} \$ 85.000,00$ além disso, 50\% exercem outra atividade além do seu empreendimento ou já trabalharam em outros locais antes de seus empreendimentos. Outro estudo aponta que além do retorno financeiro, os enfermeiros relataram que foram levados ao empreendedorismo devido à necessidade de profissional na região e à demanda de pacientes (Alexandre et al., 2019).

$\mathrm{Na}$ caracterização das tendências empreendedoras, considerando o questionário proposto por McClelland (1985) e sua pontuação recomendada (15 a 25), observou-se que características como estabelecer metas, compromisso e responsabilidade, posicionamento e autonomia foram as que obtiveram maiores médias. Enquanto, as características com menores médias, destacaram-se a persuasão, rede de contatos e a persistência. Entretanto, o estudo apontou que considerando a média, todas as características ultrapassaram o valor mínimo recomendado (Chagas et al., 2018).

Em relação a aplicabilidade da testagem de tendência empreendedora geral (TEG) estudos com enfermeiros assistenciais e enfermeiros residentes mostraram uma inclinação empreendedora muito baixa que variou nas diferentes dimensões que foram testadas. Enquanto que, o mesmo teste aplicado a docentes do curso de enfermagem com a participação de 85 docentes com idade mediana de 45 anos, com mínima de 26 anos e máxima de 63 anos, onde, 59 eram enfermeiros e 26 com outra formação profissional como, biomedicina (2), ciências biológicas (7), ciências sociais (1), farmácia (5), bioquímica (2), fisioterapia (1), matemática (1), medicina (5), nutrição (1) e odontologia obtiveram resultados com grande tendência empreendedora e, dentro daqueles que demonstraram resultados de tendência alta, a autonomia demonstrou-se como dimensão de maior prevalência e a dimensão propença em evidenciar ameaças calculadas onde obteve-se menor pontuação.

Salienta-se que O TEG é uma ferramenta que analisa e/ou observa e tem posse de uma metodolgia própria, de formato empreendedor que dispõe de cinco (5) características que concerne ao indivíduo empreendedor: busca pelo sucesso; Autossuficiência/ Capacidade ou mestria para o autocontrole; Produtividade e criatividade e Disposição/Propósitos. Para a tendência empreendedora, as cinco características são essencias (Valente, Silva \& Valente, 2018).

Aplicando-se o TEG aos enfermeiros assistenciais obtiveram-se cinco resultados relacionados à tendências empreendedoras: Propósito ou objetivo de alcançar o sucesso pessoal, por parte do empreendedor, que entende-se por resultados ou consequências do desfecho de seu empreendimento. Esta necessidade de se alcançar o sucesso está estreitamente atrelada ao cumprimento do seu objetivo pessoal. Nesta tendência, os enfermeiros residentes atingiram médias elevadas, sendo maior que 50\%. Enquanto, os docentes do curso de enfermagem apresentaram nível médio nesta tendência (Valente, Silva \& Valente, 2017; Ferreira et al., 2018).

Já na característica Autossuficiência/ Capacidade ou mestria para o autocontrole, onde há uma busca maior por autonomia, por parte do empreendedor em relação a normas e regras ou a liderança, não abre mão de sua opinião mediante 
objeção e a confiança demonstrada em sua habilidade para consumar um propósito ou encarar um estímulo novo, o resultado obtido por enfermeiros assistenciais foi conceituado como de baixa média do teste. Nos residentes esta categoria também foi avaliada como negativa, entretanto os docentes do curso de enfermagem, apresentaram alta tendência nesta característica. Portanto, encontram-se em menores proporções nos enfermeiros participantes das pesquisas (Valente, Silva \& Valente, 2017; Ferreira et al., 2018).

A terceira característica avaliada está relacionada a Tendência criativa, que inclui a aptidão para raciocínio lógico e rápido para a criatividade e assim superar dificuldades, a adoção de fórmulas criativas para lidar com algum novo problema que exija uma solução coerente. Conforme essa categoria a pontuação pelos enfermeiros assistenciais e enfermeiros residentes foi registrada como abaixo da média, o que indica que são poucos imaginativos e inovadores. Já os docentes do curso de enfermagem apresentaram uma tendência de média alta (Valente, Silva \& Valente, 2017; Ferreira et al., 2018).

A característica de Riscos calculados/moderados trás a tona a qualidade envolvida no contexto de análise com baixo quantitativo de dados à dispoisição; reflexão e análise de suas qualidades de forma imparcial; desempenho com bases informativas incompletas; ambição em propoção adequada; metas desafiadoras, mas coerentes com possibilidades reais de realização. Os enfermeiros assistenciais e os enfermeiros residentes, apresentaram índice nessa dimensão, considerado neste estudo, com uma mediana abaixo do considerado satisfatório, no teste. Os docentes do curso de enfermagem apresentaram nível médio nessa tendência (Valente, Silva \& Valente, 2017; Ferreira et al., 2018).

Quanto ao Disposição/Propósitos, é definido como uma característica profissional em pessoas que aproveitam das oportunidades concebidas e tendem a não acredidar em acontecimentos predestinados. Os enfermeiros assistenciais alcançaram pontuação média para esta propensão empreendedora, o que remete ao entendimento de que os sujeitos envolvidos sabem se beneficiar de forma proveitosa, as oportunidades, com autoconfiaça e que tem total controle sobre suas próprias decisões. Já os enfermeiros residentes ficaram acima da média assim como, os docentes do curso de enfermagem (Valente, Silva \& Valente, 2017; Ferreira et al., 2018).

Os estudos evidenciaram que o nível para a tendência ou propensão empreendedora da enfermagem no âmbito assistencial é baixo, ainda apontam que tais resultados podem ser melhorados, pelo empenho e motivação, individualmente e em conjunto com as instituições, para estimular o empreendedorismo na área (Valente, Silva \& Valente, 2017; Costa et al., 2013).

Quanto aos enfermeiros residentes o estudo apontou que apenas nas tendências de indispensabilidade de sucesso e de disposição e determinação, a porcentagem de participantes atingiu pontuação acima da média, sendo maior que 50\%, o que indica que os residentes possuíam tendência empreendedora insuficiente, apesar de serem determinados a obter sucesso (Ferreira et al., 2018).

Para a que se tenha difusão do empreendedorismo no âmbito acadêmico é necessário que se abra discussões acerca das habilidades e vivências dos docentes sobre esta temática. Os docentes da área avaliaram a liderança e o empreendedorismo apenas como competências medianas. Desta forma, pontua-se que é necessário que haja profissionais que já tenham vivências no empreendedorismo para que possam repassar os conteúdos aos estudantes, de forma adequada, no intuito de implementar processos de educação, pesquisa e desenvolvimento pessoal e profissional (Trotte et al., 2021).

Observa-se na categoria 1 que o perfil do empreendedorismo de negócio na enfermagem brasileira, está concentrado nas grandes capitais, que em geral, constitui-se de pequenas ou microempresas, registradas como atividade de enfermagem, especificamente de atendimento em consultórios, clínicas, hospitais, ambulatórios e outros serviços públicos ou privados. Constatou-se ainda que em relação ao número de cursos de graduação, a enfermagem tem baixo empreendedorismo de negócios se comparado com outras áreas da saúde. 
Sobre isso, as práticas das atribuições próprias do enfermeiro são protegidas pelo Conselho Federal de Enfermagem (COFEN), que aceitam e reconhecem sua atuação autônoma, aliadas ao regulamento dos consultórios e clínicas de enfermagem, constituindo-se em oportunidade de novos negócios promissores, com a possibilidade em diversas áreas (Cofen, 2018).

A Resolução COFEN n 567/2018, que revoga a Resolução COFEN 501/2015, e que amplifica as técnicas atualmente utilizadas por profissionais no tratamento de feridas. Em seu artigo 2, a resolução fixa que a enfermagem possua autonomia para abertura e instauração de Clínica/Consultório de Prevenção e Cuidado com feridas, respeitando as questões éticas e legais, bem como as habilidades e competência do profissional. Ainda nesta resolução, em seu anexo, irá regular a atuação dos técnicos e auxiliares de enfermagem nestes mesmos cuidados (Cofen, 2018).

Afirma-se que as organizações de saúde são constituídas por ambientes enfáticos e enigmáticos, necessitando observar as constantes e grandes alterações sociais, financeiras e ambientais, apontando-se que as inovações no campo da saúde são uma realidade na prática assistencial do/a enfermeiro/a, mesmo ainda estando associado à tecnologias virtuais, de informação ou de cuidados sistematizados em enfermagem (Becks et al., 2015).

Enfermeiras que estão na posição de gerenciamento nas organizações e serviços de saúde, acabam se vendo obrigadas a provar constantemente que são capazes criar, inovar, mesmo tendo pouca autonomia para empreender. Isto só reforça o que já foi pontuado acerca do preconceito social/trabalhista contra a mulher, típica de uma sociedade sexista que responsabiliza a enfermeira pelas dificuldades que se deparam (Richter et al., 2019).

A categoria 2 demonstra que, quanto maior o tempo de trabalho (a partir dos 12 anos) no contexto hospitalar, menor a tendência empreendedora, assim como, essa tendência empreendedora é maior nos profissionais com até 11 anos de conclusão do curso.

A questão de gênero na profissão de enfermagem se remete ao próprio nascimento da enfermagem moderna no início do século XX, nesse espaço, a história reservou para a mulher enfermeira uma mobilidade limitada, associado a docilidade, submissão, abnegação, obediência, características que se tornaram um obstáculo para o ingresso de homens na enfermagem naquela época e que perdurou por muito tempo (Coelho \& Cardoso, 2005).

A esta realidade, corrobora também a ideia que a enfermagem é a profissão do futuro, visto estar em ascensão constante e o empreendedorismo é um tema que perpassa todas as áreas do conhecimento e que deve ser ofertado para todos os discente desde o início da vida escolar, visto que este se fundamenta na busca pela construção do bem-estar individual e comunitário. Além do que foi exposto, o empreendedorismo se configura como uma ótima estratégia para a redução do desemprego (Ferreira et al., 2018).

Quanto as tendências empreendedoras, foram testadas a partir do teste de tendência empreendedora geral (TEG) realizado com enfermeiros assistenciais, enfermeiros residentes e docentes do curso de enfermagem, que apontou uma tendência empreendedora baixa dentro do conjunto enfermagem e média a alta tendência empreendedora dentro do cojunto docentes do curso de enfermagem, além disso, essa tendência é variada nas diferentes dimensões que foram testadas.

Nesse sentido, os enfermeiros assistenciais e enfermeiros residentes apresentaram um baixo nível de tendência empreendedora nas proporções a seguir: necessidade por alcançar o sucesso, autonomia/independência, Tendência criativa, Riscos calculados/moderados apresentaram uma tendência de média a alta tendência empreendedora quanto a dimensão Impulso/determinação.

Sobre esses aspectos, estudos tem mostrado que a pessoa empreendedora apresenta algumas habilidades e características de comportamento como a busca de informações, oportunidades e iniciativa; disposição para correr riscos calculados; gerenciamento; planejamento; estabelecimento de metas e de rede de contatos; exigência de qualidade e eficiência; 
comprometimento; persuasão; independência; confiança e autoconfiança; persistência; intuição; esperança; liderança e inovação.

Pontua-se ainda, o dom empreendedor de cada indivíduo, a aptidão natural para desenvolver estas ações empreendedoras. Porém, essa formação empreendedora não depende apenas de dons ou aptidões naturais, mais de uma formação qualificada, da influência acadêmica e familiar e da própria vivência (Lana et al., 2013).

O empreendedorismo busca explorar e encontrar novos horizontes que promovam o aprimoramento profissional, sentimento que pode aumentar durante a sua formação. A formação acadêmica do enfermeiro possui uma visão ampliada da realidade de um indivíduo, perpansando à ética, a universalidade, a equidade e a integralidade, junto à qualidade da assistência. E, introduzindo a questão do empreendedorismo social, vale destacar a enfermagem, que desenvolve ações comunitárias, que são serviços extremamente necessários à manutenção da saúde das camadas mais carentes da sociedade (Trotte et al., 2021).

\section{Considerações Finais}

O estudo evidenciou que o empreendedorismo de negócios na literatura da enfermagem brasileira é ainda bastante incipiente com número pequeno de publicações que demonstrem como tem sido exercido nas diversas regiões do Brasil. Evidenciou que esse empreendedorismo ocorre principalmente em grandes capitais brasileiras, em pequenas e microempresas, com atividades de enfermagem, educação, consultoria entre outras.

Os enfermeiros empreendedores de negócio na enfermagem, são em geral mulheres jovens. Apontam que esses enfermeiros em geral entram no empreendedorismo com até 11 anos de graduados e que quanto maior o tempo de trabalho em hospitais, menor a tendência a empreender e a maioria desses profissionais trabalham também em outras atividades além do empreendimento.

Quanto a tendências empreendedoras nos enfermeiros, os estudos apontam que os enfermeiros assistenciais e residentes, apresentam um nível baixo de tendência empreendedora e os docentes da área dispõe da tendência empreendedora em nível médio a alto. As particularidades do empreendedorismo mais evidenciadas nos enfermeiros assistenciais e residentes são na propensão Impulso/determinação, já os docentes enfermeiros apresentam mais evidentes as dimensões relacionadas a autonomialindependência, necessidade e busca de sucesso e Impulso/determinação.

O estudo evidencia ainda uma fragilidade do ensino de graduação em incentivar e encorajar o empreendedorismo do enfermeiro e que, portanto, esses profissionais se integram na rede de saúde hospitalar e de atenção básica de saúde pública ou privada.

Portanto, este estudo aponta uma lacuna em relação ao conhecimento do empreendedorismo de negócios na enfermagem brasileira, sendo necessário o incremento de estudos que demonstrem as experiências exitosas dos enfermeiros na área.

Espera-se com este estudo contribuir com estudos futuros, como um material consistente para subsidiar discussão nos diferentes contextos da enfermagem sobre o empreendedorismo de negócios na perspectiva de geração de trabalho e visão empresarial, visando incentivar a discussão e formação acadêmica de enfermagem de forma empreendedora.

\section{Referências}

Alexandre, A. C. S., et al. (2019). Arte e Ciência do Cuidar: Alteridade, Estabelecidos e Outsiders na Autonomia do Enfermeiro como Profissional Liberal. Revista de Pesquisa: Cuidado é Fundamental Online, 11(2), 370.

Araújo, M. R. A., \& Nunes, E. C. D. A. (2018). Empreendedorismo em enfermagem: um caminho promissor à luz da teoria de horta. Revista Saúde, 12.

Backes, D. S., et al. (2015). Incubadora de Aprendizagem: ferramenta indutora do empreendedorismo na Enfermagem. Revista Brasileira de Enfermagem, 68(6), 1103-1108. 
Botelho, L. L. R., Cunha, C. C. de A. \& Macedo, M. (2011). O método da revisão integrativa nos estudos organizacionais. Gestão e Sociedade - Belo Horizonte, 5(11), 121-136.

Chagas, S. C. et al. (2018). O empreendedorismo de negócios entre enfermeiros. Revista Enfermagem UERJ, $26,31469$.

Coelho, E. \& Cardoso A. (2005). Gênero, saúde e enfermagem. REBEn, 58(1), 345-348.

Colichi, R. M. B. \& Lima, S. A. M. (2018). Empreendedorismo na enfermagem: comparação com outras profissões da saúde. Revista Eletrônica de Enfermagem, 20, 1-11.

Conselho Federal de Enfermagem-Cofen (2018). Resolução nº 0568, de 2018. Regulamento dos consultórios e centros de enfermagem. Diário Oficial, Brasília, DF. http://www.cofen.gov.br/resolucao-cofen-no-0568-2018_60473.html.

Costa, F. G. et al. (2013). Tendências empreendedoras dos enfermeiros de um hospital universitário. Revista Gaúcha de Enfermagem, 34(3), 147-154.

Copelli, F. H. da S., Erdmann, A. L., \& Santos, J. L. G. dos. (2019). Empreendedorismo na Enfermagem: revisão integrativa da literatura. Revista Brasileira de Enfermagem, 72(Suppl. 1), 289-298.

Dornelas, J. C. A. (2016). Empreendedorismo: transformando idéias em negócios. (5a ed.), Empreende/LTC.

Ferreira, A. M. D. et al. (2018). Perfil empreendedor entre residentes de enfermagem. Revista Baiana de Enfermagem, 32, 1-9.

Lana, J. et al. (2013). A relação das competências empreendedoras e da conduta intraempreendedora no setor de serviços educacionais. Revista Pensamento Contemporâneo em Administração, 7(2), 77-95.

Lima, T. F. da S. et al. (2021). Variáveis climáticas e sua relação com doenças de origem infecciosa: Uma revisão integrativa. Research, Society and Development, 10(2), e7910212126. https://doi.org/10.33448/rsd-v10i2.12126

McClelland, D. C. (1985). Characteristics of successful entrepreneurs. The Journal of Creative Behavior, 21(3), 219-233.

Moher, D., et al. (2009). Preferred reporting items for systematic reviews and meta-analyses: The PRISMA statement. PLoS Medicine. 6 (7).

Moura, J. de M. \& Brum, Z. P. de. (2017). A enfermagem do ponto de vista empreendedor. Revista Interdisciplinar em Ciências da Saúde e Biológicas, 1(1)11-19.

Pereira, A. S., et al. (2018). Metodologia da pesquisa científica. UFSM. https://repositorio.ufsm.br/bitstream/handle/1/15824/Lic_Computacao_MetodologiaPesquisa-Cientifica.pdf?sequence $=1$.

Richter, S. A. et al. (2019). Ações empreendedoras em enfermagem: desafios de enfermeiras em posição estratégica de liderança. Acta Paulista de Enfermagem, 32(1), 46-52.

Santos, C. M. D. C., Pimenta, C. A. D. M. \& Nobre, M. R. C. (2007). A estratégia PICO para a construção da pergunta dr pesqui sa e busca de evidências. Revista Latino-Americana de Enfermagem, 15(3), 508-511.

Santos, W. M. dos, Secoli, S. R. \& Püschel, V. A. de A. (2018). A abordagem do Joanna Briggs Institute para revisões sistemáticas. Revista Latino-Americana de Enfermagem, 26. e3074.

Soares, C. B. et al. (2014). Revisão Integrativa versus Revisão Sistemática. Reme: Revista Mineira de Enfermagem, 12(4), 758-764.

Souza, M. T. de, Silva, M. D. da, \& Carvalho, R. de. (2010). Revisão integrativa: o que é e como fazer. Einstein (São Paulo), 8(1), $102-106$.

Teixeira, E. et al. (2014). RIL métodos de revisão. Revista de Enfermagem da UFPI, 2(5), 3.

Trotte, L. A. C. et al. (2021). Tendência empreendedora de estudantes de enfermagem: comparação entre alunos de graduação iniciantes e concluintes. Revista Latino-Americana de Enfermagem, 29, e3402.

Ursi, E. S. \& Galvão, C. M. (2015). Avaliação das escalas de risco para úlcera por pressão em pacientes críticos: uma coorte prospectiva. Acta Paul Enferm. 23(1), 28-35.

Valente, G. S. C., Silva, A. C. da P. \& Valente, G. L. C. (2018). O empreendedorismo como uma ferramenta para atuação do enfermeiro. Rev. enferm. UFPE on line. 11(4),1595-602. 